\title{
The use of tris-hydroxymethyl aminomethane in the emergency department
}

eISSN: $2383-4625$

\section{Christina Lu, Evan Leibner, Brian Wright}

Department of Emergency Medicine, Stony Brook University, Stony Brook, NY, USA

Treatment of critically ill patients is a multi-faceted problem. Often the physician is faced with multiple complex tasks that range from correctly diagnosing the underlying disease process to appropriately managing the hemodynamics and homeostasis. Critically ill patients commonly have acid-base abnormalities, especially acidosis. Critical care dogma teaches that treatment of the primary condition will lead to a correction of the acidosis. That acidosis, however, can be so severe that it needs to be addressed before the underlying medical condition can be reversed. This review will discuss tris-hydroxymethyl aminomethane (THAM). THAM is a rarely used buffer approved by the Food and Drug Administration for treatment of metabolic acidosis associated with cardiac bypass surgery and metabolic acidosis associated with cardiac arrest. ${ }^{1}$

Many studies have examined the role of sodium bicarbonate $\left(\mathrm{NaHCO}_{3}\right)$ in alkalinizing blood $\mathrm{pH} . \mathrm{NaHCO}_{3}$ has been shown to have limited effects or to be ineffective. ${ }^{2}$ One of the chief reasons for the limited efficacy of $\mathrm{NaHCO}_{3}$ is the way it is processed in the body:

$\mathrm{HCO}_{3}{ }^{-}+\mathrm{H}^{+} \leftrightarrow \mathrm{H}_{2} \mathrm{CO}_{3} \leftrightarrow \mathrm{CO}_{2}+\mathrm{H}_{2} \mathrm{O}$

To alkanize the blood, patients much be able to eliminate $\mathrm{CO}_{2}$ by increasing their minute ventilation. This is often not realistic in patients with acute circulatory shock and/or respiratory failure. The resultant build up of $\mathrm{CO}_{2}$ drives the equation to the left and creates more acid. In addition, the intracellular $\mathrm{pH}$ effects of bicarbonate are not well established. $\mathrm{CO}_{2}$ readily diffuses across cell membranes and generation of more $\mathrm{CO}_{2}$ may in fact create intracellular acidosis. ${ }^{3}$

An alternative option to sodium bicarbonate for treating acidosis in the severely ill is THAM. This little known medication has been around for decades. THAM was first introduced into laboratory practice in the 1940's and then in vivo studies in the late 1950's. It is a weak amino alcohol base, which exerts its buffering capabilities by binding both to carbon dioxide and metabolic
Received: 20 July 2016 Revised: 22 August 2016 Accepted: 22 August 2016

Correspondence to: Brian Wright Department of Emergency Medicine, Stony Brook University, Hsc, Level 4, Room 080, Stony Brook, NY 11794, USA

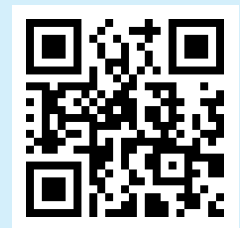

How to cite this article:

Lu C, Leibner E, Wright B. The use of trishydroxymethyl aminomethane in the emergency department. Clin Exp Emerg Med 2016;3(4):264-265

This is an Open Access article distributed under the terms of the Creative Commons Attribution Non-Commercial License (http:// creativecommons.org/licenses/by-nc/4.0/). 
acids through the following mechanisms:

$$
\begin{aligned}
& \mathrm{R}-\mathrm{NH}_{2}+\mathrm{H}_{2} \mathrm{O}+\mathrm{CO}_{2} \rightarrow \mathrm{R}^{-} \mathrm{NH}_{3}{ }^{+}+\mathrm{HCO}_{3}{ }^{-} \\
& \mathrm{R}-\mathrm{NH}_{2}+\mathrm{H}^{+} \longrightarrow \mathrm{R}-\mathrm{NH}_{3}{ }^{+}
\end{aligned}
$$

THAM is thought to exert effects in both the extracellular space and intracellular space. ${ }^{5}$ THAM is also thought to be a more effective buffer than $\mathrm{NaHCO}_{3}$ in the physiological range of blood $\mathrm{pH}$ because of a higher pKA (7.8 compared to 6.1 for $\mathrm{NaHCO}_{3}$ ). Unlike sodium bicarbonate, which requires patients to augment their alveolar minute ventilation to eliminate $\mathrm{CO}_{2}$, THAM forms $\left(\mathrm{R}-\mathrm{NH}_{3}{ }^{+}\right)$which is renally excreted by glomerular filtration. The protonated buffer gets eliminated in the urine, which results in THAM being effective in a closed system independent of pulmonary function.

The closed system buffering capabilities of THAM makes it highly useful in disease processes such as ARDS, ${ }^{6}$ where $\mathrm{CO}_{2}$ elimination is hindered by permissive hypercapnea strategies employed to prevent further lung injury and increased dead space minute ventilation. It also has a role in critically ill patients with diabetic ketoacidosis with severe acidemia $(\mathrm{pH} \leq 7.1)$ where $\mathrm{CO}_{2}$ elimination is maximal. ${ }^{4}$ THAM has been proposed to be effective in low cardiac output disease states (venous hypercapnea) such as sepsis, hemorrhagic shock, and cardiogenic shock. As it does not increase the serum sodium, it also may be the alkalinizing agent of choice in patients with hypernatremia.?

While it should be widely available, THAM's production in the United States has recently been discontinued. Of the remaining supplies, THAM is available in a concentration of $0.3 \mathrm{~mol} / \mathrm{L}$ and at a pH of 8.6. It comes in $500 \mathrm{~mL}$ bottles, and may be administered through a large peripheral vein. Dosing is based on the equation:

Volume of $0.3 \mathrm{~mol} / \mathrm{L}$ THAM $(\mathrm{mL})=$ bodyweight $(\mathrm{kg}) \times$ base deficit $(\mathrm{mEq} / \mathrm{L}) \times 1.1^{1}$

The maximal daily dose per day is $15 \mathrm{mmol} / \mathrm{kg}$ in adults. A reasonable alternative formula to avoid overcorrection is to correct half the base deficit. Using the above formula, a loading dose of $25 \%$ to $50 \%$ of the calculated dose is given intravenously over 5 to 10 minutes and the balance administered over 1 to 2 hours. $^{4}$

THAM is contraindicated in renal failure (acute kidney injury, oliguria, or anuria) due to its reliance on renal elimination. Additionally it can also cause respiratory depression, hypoglycemia, hyperkalemia, and hypotension. ${ }^{7}$ Much of the effects of respiratory depression and hypoglycemia are related to the dose and speed of medication administration. As such, the drug requires a slower infusion and it is not yet fully determined what concomitant medications can be given via the same $\mathrm{IV} .{ }^{8}$ In the past, THAM was formulated as a base with $\mathrm{pH}$ of 10.2, which led to skin necrosis with extravasation. It is less of an issue now with the $0.3 \mathrm{~mol} / \mathrm{L}$ concentration, but the medication continues to be a vesicant and can cause skin irritation. ${ }^{4}$

THAM has been used as a $\mathrm{CO}_{2}$ buffer for years in the lab and during cardiac surgery, but is not widely known by emergency physicians or intensivists. Much of the work done on THAM was done in the 1960's. Currently there are no randomized controlled studies on the effectiveness of THAM and no comparison studies to $\mathrm{NaHCO}_{3}$. Recent renewed interest and initial success with the use of THAM in critically ill patients has shown it to be a promising alkalinization agent, especially in respiratory failure and low cardiac output states. While currently there are no manufacturers in USA, a renewed interest and awareness of this hopefully will bring change.

\section{CONFLICT OF INTEREST}

No potential conflict of interest relevant to this article was reported.

\section{REFERENCES}

1. Tham Solution. Tromethamine injection package insert. Lake Forest, IL: Hospira; 2005.

2. Cooper DJ, Walley KR, Wiggs BR, Russell JA. Bicarbonate does not improve hemodynamics in critically ill patients who have lactic acidosis: a prospective, controlled clinical study. Ann Intern Med 1990;112:492-8.

3. Gehlbach BK, Schmidt GA. Bench-to-bedside review: treating acid-base abnormalities in the intensive care unit. The role of buffers. Crit Care 2004:8:259-65.

4. Nahas $G G$, Sutin $K M$, Fermon $C$, et al. Guidelines for the treatment of acidaemia with THAM. Drugs 1998;55:191-224.

5. Holmdahl MH, Wiklund L, Wetterberg $T$, et al. The place of THAM in the management of acidemia in clinical practice. Acta Anaesthesiol Scand 2000;44:524-7.

6. Kallet RH, Jasmer RM, Luce JM, Lin LH, Marks JD. The treatment of acidosis in acute lung injury with tris-hydroxymethyl aminomethane (THAM). Am J Respir Crit Care Med 2000;161(4 Pt 1):1149-53.

7. Hoste EA, Colpaert K, Vanholder RC, et al. Sodium bicarbonate versus THAM in ICU patients with mild metabolic acidosis. J Nephrol 2005;18:303-7.

8. Sooriyakumaran P, Geier C. Your patient in extremis: THAM to the rescue? [Internet]. [place unknown]: Academic Life in Emergency Medicine; 2015 [cited 2016 Sep 5]. Available from: http://www.aliem.com/2015/patient-extremis-tham-rescue. 